\title{
High Sensitive C-Reactive Protein as a Pro-inflammatory marker for the components of metabolic syndrome
}

\author{
Ravi A ${ }^{1}$, Thilak Babu' ${ }^{2}$, Shankar $\mathbf{R}^{3}$ \\ ${ }^{1}$ Dr. Ravi Arulanantham, Associate Professor, Department of Internal Medicine, Thanjavur Medical College, Thanjavur, \\ TN, South India, ${ }^{2}$ Dr. Thilak Babu, Post Graduate, Department of Internal Medicine, Thanjavur Medical College, \\ Thanjavur, TN, South India, ${ }^{3}$ Dr. Shankar Radhakrishnan, Associate Professor, Department of Community Medicine, \\ VMKVMCH, Salem.
}

Address for Correspondence: ${ }^{3}$ Dr. Shankar Radhakrishnan, Email: shnkr_radhakrishnan@yahoo.com

\begin{abstract}
Background: Metabolic Syndrome (MS) is a clinical entity characterized by the cluster of insulin resistance, glucose intolerance, atherogenic lipid profile, hypertension, abdominal obesity.CRP (C- reactive protein) is an acute-phase reactant and nonspecific marker of inflammation, produced predominantly in hepatocytes as a pentamer of identical subunits in response to several cytokines. The CRP in plaque deposition is highly complex, exerting pro-atherogenic effects in many cells involved in atherosclerosis. Materials and Methods: A cross sectional study was conducted by Department of Internal Medicine of Government Thanjavur Medical College Hospital, Thanjavur, Tamilnadu, South India, a tertiary care centre catering to rural population. A total of hundred patients were included in the study. The components of metabolic syndrome were defined according to the modified National Cholesterol Education Program Adult Treatment Panel III (NCEP-ATP III) criteria and World Health Organization (WHO) guidelines for South Asians. According to the guidelines, hs-CRP level of less than $1.0 \mathrm{mg} / \mathrm{L}$ is considered as low risk, 1.0 to $3.0 \mathrm{mg} / \mathrm{L}$ as moderate risk, and greater than $3.0 \mathrm{mg} / \mathrm{L}$ as high risk. Blood sample was drawn in the morning after 10 hours of fasting, to measure venous plasma glucose, serum total cholesterol, serum high density lipoprotein (HDL) cholesterol,serum triglyceride levels (TG) and hsCRP. Results: A highly positive correlation was established between hS-CRP and all the components of metabolic syndrome except for HDL cholesterol which showed a negative correlation. A univariate type of analysis had shown a statistically significant association between hsCRP and the metabolic syndrome components. The result further showed that $\mathrm{hS}-\mathrm{CRP}$ level was found to be $1.12 \mathrm{mg} / \mathrm{dl}$ when only one component of metabolic syndrome was present, whereas the mean level had raised to $2.89 \mathrm{mg} / \mathrm{dl}$ when all the five components of metabolic syndrome was present. Conclusion: Hence hs-CRP can probably be used as a surrogate marker of chronic inflammation in patients with metabolic syndrome and the patients with high hsCRP should primarily be targeted with life style modification at an early age, treatment with low dose aspirin and lipid lowering medications before it culminates in overt CVD.
\end{abstract}

Keywords: Metabolic syndrome, High sensitive C-reactive protein, Association and correlation

\section{Introduction}

The prevalence and the incidence of non-communicable diseases is increasing worldwide with chronic diseases accounting for $60 \%$ of all deaths and $80 \%$ of these happening in the developing nations [1]. Over the last two decade, obesity is becoming a major health problem worldwide, irrespective of socio-economic status and geographical regions. Along with it there is a rise in the prevalence of Metabolic Syndrome (MS) which is a

Manuscript received $26^{\text {th }}$ April 2016

Reviewed: $10^{\text {th }}$ May 2016

Author Corrected: $25^{\text {th }}$ May 2016

Accepted for Publication 11 $1^{\text {th }}$ June 2016 clinical entity characterized by the cluster of insulin resistance, glucose intolerance, atherogenic lipid profile, hypertension, abdominal obesity. India is estimated to have $1 / 3^{\text {rd }}$ of its population living with metabolic syndrome and majority of them are women [2-4]. Because of theincreased risks for morbidity and mortality associated with this syndrome, the knowledge of its dimension is critical for planning prevention, and health care interventions. Studies have proved that those with metabolic syndrome have fivefold risk of developing Type 2 Diabetes Mellitus (T2DM) and 
three fold risk of developing cardiovascular diseases [5].

\begin{abstract}
Although individual components of metabolic syndrome had independently contributed to the increased cardiovascular risk, in concert, they do not explain the increased propensity of vascular disease in patients with MS, and the precise mechanisms for this increased propensity still remains unclear. Inflammation is pivotal in all phases of atherosclerosis from foam cell formation to culmination in acute coronary syndromes. Also, several lines of evidence demonstrate that diabetes is a proinflammatory state. It appears that lowgrade chronic inflammation is one of the key feature of metabolic syndrome and it could contribute to increased risks of both CVD and diabetes in those people [6].
\end{abstract}

CRP (C- reactive protein) is an acute-phase reactant and nonspecific marker of inflammation, produced predominantly in hepatocytes as a pentamer of identical subunits in response to several cytokines [7]. Interleukin (IL)-6, one of the most potent drivers of CRP production which is released from activated leukocytes in response to infection or trauma and from vascular smooth muscle cells in response to atherosclerosis. CRP directly binds highly atherogenic oxidized low-density lipoprotein cholesterol (LDL-C) and is present within lipid-laden plaques [8]. The possible mechanistic role of CRP in plaque deposition is highly complex, exerting pro-atherogenic effects in many cells involved in atherosclerosis [9]. CRP may facilitate monocyte adhesion and transmigration into the vessel wall, which is the most critical and the early step in the atherosclerotic process [10]. Furthermore CRP, is a proinflammatory trigger in plaque deposition, leading to macrophage infiltration of both adipose tissue and atherosclerotic lesions [11].

Thehigh-sensitivity CRP (hs- CRP) varies from 0 - 5 $\mathrm{mg} / \mathrm{L}$ in healthy young adults and is significantly associated with the metabolic syndrome and its components [12]. It is highly predictive of subsequent risk of cardiovascular events and diabetes mellitus in apparently healthy men and women. Indeed, higher CRP levels provide additional prognostic information on cardiovascular risk in patients with metabolic syndrome [13].

Very little has been documented on this topic from India. The present study was designed to study the relationship of hs-CRP with the components of metabolic syndrome.

\section{Materials and Methods}

This cross sectional population based study was conducted by Department of Internal Medicine of Government Thanjavur Medical College Hospital, Thanjavur, Tamilnadu, South India, a tertiary care centre catering to rural population. The study period extended between June 2014 and October 2015. The study protocol was approved by the institutional ethics committee before initiation of the study. Informed consent was obtained from each patient before enrolling. The total number of patients included in our study was 100 .

The data were recorded from each subject with an inperson interview by administering a specific questionnaire. The components of metabolic syndrome were defined according to the modified National Cholesterol Education Program Adult Treatment Panel III (NCEP-ATP III) criteria and World Health Organization (WHO) guidelines for South Asians [14,15]. According to the guidelines, hs-CRP level of less than $1.0 \mathrm{mg} / \mathrm{L}$ is considered as low risk, 1.0 to 3.0 $\mathrm{mg} / \mathrm{L}$ as moderate risk, and greater than $3.0 \mathrm{mg} / \mathrm{L}$ as high risk $[16,17]$.

Anthropometric measurements were recorded and the BMI was calsulated. Weight (in $\mathrm{kg}$ ) was taken on a standardized weighing scale with patient wearing light clothing and in bare feet and the measurement was taken to the nearest of $0.1 \mathrm{~kg}$. Height (in $\mathrm{m}^{2}$ ) was measured on a standardized chart. Waist circumference (WC) and hip circumference (HC) were measured with a non-stretchable measuring tape for obtaining waist to hip ratio (WHR).

WC was measured at the midpoint between the anterior superior iliac spine and the lowest rib. HC was measured at the most protuberant part of gluteus maximus. The WHR was defined as the ratio of waist girth to the circumference of the hips. BP was measured in a sitting posture and the readings were taken for three times and the average was taken for analysis. Blood sample was drawn in the morning after 10 hours of fasting, to measure venous plasma glucose, serum total cholesterol, serum high density lipoprotein (HDL) cholesterol, and serum triglyceride levels (TG).

Serum glucose was measured by the glucose oxidase method; plasma triglycerides, total holesterol and HDLcholesterol were measured by enzymatic colorimetric assay using an auto-analyser. Serum hs-CRP levels 
were determined by particle enhanced immuneturbidometric assay using BTS 350 BIOSYSTEMS, SPAIN. All the data were entered in the SPSS version 16 for analysis. Mean, SD and the 95\% CI was calculated for all the parametric variables and the pearson's correlation test was used to derive the statistical inference between the hS-CRP and the parameters of metabolic syndrome.

\section{Results}

The age and gender wise distribution of the study population based on their components of metabolic syndrome was shown in table 1 . Of the total 100 study subjects 58 were males and 42 were females. Majority of the study subjects were in the age group of between 50 - 60 years. The mean age among males was 51.6 and for females it was 52.34 years. The most common component of the metabolic syndrome in the age group of less than 60 years was increase in fasting blood glucose and obesity, whereas in the age group of more than 60 years hypertension was found to be the most common component.

Table-1: Components of metabolic syndrome in the study population according to their age and gender.

\begin{tabular}{|c|c|c|c|c|c|c|}
\hline Age group & Gender & $\begin{array}{c}\text { Increase } \\
\text { fasting } \\
\text { glucose levels }\end{array}$ & Obesity & $\begin{array}{c}\text { Increased } \\
\text { triglycerides } \\
\text { levels }\end{array}$ & Hypertension & $\begin{array}{l}\text { Low serum } \\
\text { HDL levels }\end{array}$ \\
\hline \multirow[t]{2}{*}{$30-40(n=18)$} & $\operatorname{Male}(n=10)$ & $7(70 \%)$ & $8(80 \%)$ & $6(60 \%)$ & $7(70 \%)$ & $5(50 \%)$ \\
\hline & Female $(n=8)$ & $6(75 \%)$ & $7(87.5 \%)$ & $4(50 \%)$ & $3(37.5 \%)$ & $4(50 \%)$ \\
\hline \multirow[t]{2}{*}{$41-50(n=29)$} & Male $(n=18)$ & $14(77.7 \%)$ & $12(66.6 \%)$ & $10(55.5 \%)$ & $11(61.1 \%)$ & $9(50 \%)$ \\
\hline & $\begin{array}{c}\text { Female } \\
(n=11)\end{array}$ & $8(72.7 \%)$ & $9(81.1 \%)$ & $7(63.6 \%)$ & $5(45.4 \%)$ & $6(54.5 \%)$ \\
\hline \multirow[t]{2}{*}{$51-60(n=44)$} & Male $(n=25)$ & $20(80 \%)$ & $18(72 \%)$ & $19(76 \%)$ & $20(80 \%)$ & $17(68 \%)$ \\
\hline & $\begin{array}{c}\text { Female } \\
(n=19)\end{array}$ & $16(84.2 \%)$ & $17(89.4 \%)$ & $15(78.9 \%)$ & $9(47.3 \%)$ & $10(52.6 \%)$ \\
\hline \multirow[t]{2}{*}{$>60(n=9)$} & Male $(n=5)$ & $4(80 \%)$ & $2(40 \%)$ & $3(60 \%)$ & $5(100 \%)$ & $3(60 \%)$ \\
\hline & Female $(n=4)$ & $4(100 \%)$ & $3(75 \%)$ & $3(75 \%)$ & $2(50 \%)$ & $2(50 \%)$ \\
\hline
\end{tabular}

The mean, SD and 95\% CI of the various serological parameters measured among the study population was shown in table 2. The mean hS-CRP level was found to be $2.56 \mathrm{mg} / \mathrm{d}$, which was in the range of moderately elevated and for about $25 \%$ of the patients the levels were more than $3 \mathrm{mg} / \mathrm{dl}$.

The mean of other serological parameters like fasting blood glucose, trigly cerides and HDL cholesterol levels were $128.4 \mathrm{mg} / \mathrm{dl}, 156.3 \mathrm{mg} / \mathrm{dl}$ and $32.4 \mathrm{mg} / \mathrm{dl}$ respectively. So, all the blood parameters were found to be moderately elevated than the normal except the HDL levels which was lower than the normal.

Table-2: Mean, SD and $95 \% \mathrm{CI}$ of the various serological parameters measured among the study population.

\begin{tabular}{|c|c|c|c|}
\hline Serological parameter & Mean $(\mathbf{m g m} / \mathbf{d l})$ & SD & 95\% CI \\
\hline Fasting blood glucose & 128.46 & 9.42 & $121.42-135.36$ \\
\hline Triglycerides & 156.35 & 8.45 & $148.44-162.56$ \\
\hline HDL & 32.46 & 3.62 & $28.34-34.48$ \\
\hline hS CRP & 2.56 & 0.71 & $1.84-3.12$ \\
\hline
\end{tabular}

The correlation between hS-CRP and other metabolic syndrome parameters were assessed by applying peasrson's correlation test. It had shown a highly positive correlation between hS-CRP and all the components of metabolic syndrome, which means as the individual parameter value increases the levels of hS-CRP also increases.

A weak positive correlation was seen for triglycerides $(\mathrm{r}=0.601)$ and a weak negative correlation (one value decreases the other value increases) was seen for HDL cholesterol (table 3 ). 
Table- 3: Pearson's correlation between hs-CRP and the parameters of metabolic syndrome.

\begin{tabular}{|c|c|c|}
\hline \multirow{4}{*}{ hS - CRP } & $\begin{array}{c}\text { Parameters of metabolic } \\
\text { syndrome }\end{array}$ & $\begin{array}{c}\text { Pearson correlation } \\
\text { r value }\end{array}$ \\
\cline { 2 - 3 } & BMI & 0.789 \\
\cline { 2 - 3 } & Waist circumference & 0.816 \\
\cline { 2 - 3 } & Systolic BP & 0.899 \\
\cline { 2 - 3 } & Diastolic BP & 0.798 \\
\cline { 2 - 3 } & Fasting blood glucose & 0.909 \\
\cline { 2 - 3 } & Triglycerides & 0.601 \\
\cline { 2 - 3 } & HDL & -0.442 \\
\hline
\end{tabular}

Anunivariate type of analysis was made to find out the association between hS-CRP and the individual component of metabolic syndrome. It was proved that there was a statistically significant association between increase in the hS-CRP levels and the increase fasting sugar, obesity, systolic blood pressure and the diastolic blood pressure $(\mathrm{P}<.001)$, but the increased triglycerides and reduced HDL though showed an association but was not found to be statistically significant (P>.05) (table 4).

Table-4: Univariate analysis between hs-CRP and the metabolic syndrome parameters.

\begin{tabular}{|c|c|c|c|}
\hline \multicolumn{2}{|c|}{ Metabolic syndrome parameter } & \multirow{2}{*}{$\begin{array}{c}\text { hS - CRP } \\
\text { Mean (95\% CI) } \\
2.34(1.91-2.54) \\
\end{array}$} & \multirow{2}{*}{\begin{tabular}{|c|} 
P value \\
0.001
\end{tabular}} \\
\hline \multirow[t]{2}{*}{ Obesity } & Yes & & \\
\hline & No & $0.89(0.81-1.12)$ & \\
\hline \multirow{2}{*}{$\begin{array}{c}\text { Increased fasting blood } \\
\text { glucose }\end{array}$} & Yes & $2.41(1.95-2.86)$ & \multirow[t]{2}{*}{0.0001} \\
\hline & No & $0.90(0.81-1.11)$ & \\
\hline \multirow[t]{2}{*}{ Increased systolic BP } & Yes & $2.32(1.81-2.62)$ & \multirow[t]{2}{*}{0.001} \\
\hline & No & $0.78(0.65-1.12)$ & \\
\hline \multirow[t]{2}{*}{ Increased diastolic BP } & Yes & $2.31(1.80-2.59)$ & \multirow[t]{2}{*}{0.001} \\
\hline & No & $0.79(0.66-1.11)$ & \\
\hline \multirow{2}{*}{$\begin{array}{c}\text { Increased triglycerides } \\
\text { level }\end{array}$} & Yes & $1.86(1.35-2.21)$ & \multirow[t]{2}{*}{0.0812} \\
\hline & No & $1.12(0.89-1.42)$ & \\
\hline Decrease HDL levels & Yes & $1.74(1.24-2.16)$ & 0.076 \\
\hline
\end{tabular}

The hS-CRP levels were steadily increasing as the number of the components of metabolic syndrome increases. It mean hS-CRP level was found to be 1.12 when only one component of metabolic syndrome was present, whereas the mean level raises to 2.89 when all the five components of metabolic syndrome was found to be present in the individual and this level of increase was found to be statistically significant $(\mathrm{p}<.001)$ (table 5).

Table- 5: Mean hS-CRP levels for the number of metabolic syndrome components.

\begin{tabular}{|c|c|c|}
\hline Number of metabolic syndrome components & Mean hS-CRP $(\mathbf{m g} / \mathbf{d l})$ & \\
\hline One component & 1.12 & $<.0001$ \\
\hline Two components & 1.42 \\
\hline Three components & 1.92 \\
\hline Four components & 2.46 \\
\hline All five components & 2.89 \\
\hline
\end{tabular}

\section{Discussions}

The risk factors for coronary artery diseases such as central obesity, high blood pressure, and diabetes, the components of metabolic syndrome had a shown a strong association with increased levels of CRP. Therefore, hS-CRP can be considered as a marker of low grade inflammation in the pathogenesis of 
cardiovascular diseases (CVD) [12]. Many studies had shown that metabolic syndrome with increased CRP leading on to morbidity and mortality due to CAD. A well-known study is the Framingham Off spring Study which had shown thatmetabolic syndrome and CRP are associated with increased cardiovascular morbidity and mortality $[18,19]$.

The prevalence of metabolic syndrome in men and women has been varyingly addressed. In other published studies the prevalence of metabolic syndrome was more common in females than males [20]. In our study with 100 patients, metabolic syndrome was found to be slightly more common in males $(58 \%)$ than in females $(42 \%)$. As our study was a hospital based and the more number of males might be a reflection of social bias.

In our study majority of the subjects with metabolic syndrome were in the age group between $40-60$ years. The study done by the National Health and Nutrition Examination Survey (NHANES III) [21] had shown that the incidence of metabolic syndrome was steadily increasing after the age of 40 years and the study done by guptaetal [22] had also proven the same.

Our study had shown that the mean levels of fasting glucose, triglycerides and hS-CRP of the study subjects with metabolic syndrome are clearly above the normal limits and similar type of results was also established by a study done by SudhaVidyasagaretal [23].

The present study had shown a positive correlation between hsCRP level and the components of metabolic syndrome and the results are almost in parwith the studies done by Ridkeretal [24] and Malik etal [25]. Whereas contradicting to our results a study done by Vikrametal [26] and Muktaetal [27] had shown no correlation between hsCRP and the metabolic syndrome components and the reason quoted for it was concomitant medications like aspirin and antidiabetic agents taken by the patients. Aspirin and statins are known to reduce vascular inflammation, which may result in reduced levels of CRP in those patients.

In the current study, by doing a univariate type of analysis we found a significant association between hsCRP and the components of the metabolic syndrome and it was more so with obesity, diabetes and hypertension. Several studies have showed that central obesity is associated with high hs-CRP levels [28,29]. In some other studies, it was observed that diabetes mellitus was associated with elevated hs-CRP levels [30,31]. A positive association between high blood pressure and elevated hs-CRP was noted in some studies $[32,33]$.

In our study we found that increasing the number of components of metabolic syndrome the mean hsCRP levels had increased significantly, similar to our study a study conducted by Bo etal had also shown a significant positive linear association with number of abnormal features of the metabolic syndrome and the same was also proven by a study done by SudhaVidhyasagaretal [24].

Recent reviews had shown that there was a strong consideration for the measurement of CRP to be added in the metabolic syndrome components as it was closely related with other components of the syndrome [34].

Therefore, if subclinical inflammation is indeed another aspect of metabolic syndrome, anti-atherogenic treatment in the form of antiplatelets and statins could be sought due to their pleotrophic effects. Additionally, the advantage of nonpharmacological interventions, such as weight reduction or regular practice of exercise, may be translated into lower CRP levels due to reduced inflammation, thus providing benefits that go beyond solely decreasing glucose levels or obesity prevalence [35].

\section{Conclusion}

In conclusion, a positive correlation was found between hs-CRP and the components of metabolic syndrome like obesity, diabetes mellitus and hypertension. There was a linear increase in hs-CRP with increasing number of metabolic syndrome components. Hence hs- CRP can probably be used as a surrogate marker of chronic inflammation in patients with metabolic syndrome. These patients represent a group where primary prevention therapies like life style modification at an early age, treatment with low dose aspirin, lipid-lower ingmedications should be targeted before it culminates in overt CVD.

Acknowledgements: The authors would like to thank the administrative, nursing, and secretarial staff of the departments of Internal Medicine and Biochemistry, Govt. Thanjavur Medical College, Thanjavur, TN, South India.

Funding: Nil, Conflict of interest: None initiated. Permission from IRB: Yes 


\section{References}

1. Abdallah S Daar. Chronic Non-communicable Diseases as a Threat for All. Sultan QaboosUniv Med J. 2010 Dec; 10(3): 306-309.

2. Misra A, Khurana L. Obesity and the metabolic syndrome in developing countries. J Clin Endo crinol Metab. 2008 Nov; 93 (11 Suppl 1):S9-30. doi: 10. 1210/ jc.2008-1595.

3. Das M, Pal S, Ghosh A. Prevalence of cardiovascular disease risk factors by habitat: A study on adult Asian Indians in West Bengal, India. AnthropolAnz. 2011; 68 (3):253-64.

4. Kanjilal S, Shanker J, Rao VS, Khadrinarasimhaih NB, Mukherjee M, Iyengar SS. Prevalence and component analysis of metabolic syndrome: an Indian atherosclerosis research study perspective. Vasc Health Risk Manag. 2008;4(1):189-97.

5. Sookoian S, Pirola C. Metabolic syndrome: from the genetics to the pathophysiology. Curr Hypertens Rep 2011; 13 (2): 149-157.doi:10.1007/s11906-010-0164-9.

6. Khot UN, Khot MB, Bajzer CT, Sapp SK, Ohman EM, Brener S Jetal. Prevalence of conventional risk factors in patients with coronary heart disease. JAMA 2003; 290 (7):898-904.

7. Norata GD, Marchesi P, PulakazhiVenu, Pasqualini F, Anselmo A, Moalli F, et al. Deficiency of the long pentraxin PTX3 promotes vascular inflammation and atherosclerosis. Circulation 2009;120 (8):699-708.doi: 10.1161/CIRCULATIONAHA.108.806547.

8. Libby P. Inflammation in atherosclerosis. Nature 2002;420 (6917):868-74.

9. Zhang YX, Cliff WJ, Schoefl GI, Higgins G. Coronary C-reactive protein distribution: its relation to development of atherosclerosis. Atherosclerosis 1999; 145(2):375-9.

10. Libby P, Nahrendorf M, Pittet MJ, Swirski FK. Diversity of denizens of the atherosclerotic plaque: not all monocytes are created equal. Circulation 2008; 117(25):3168-70.doi:10.1161/CIRCULATIONAHA. 108.783068 .

11. Kones R. Primary prevention of coronary heart disease: integration of new data, evolving views, revised goals, and role of rosuvastatin in management. A comprehensive survey. Drug Des Devel Ther 2011;5: 325-80.doi: 10.2147/DDDT.S14934.

12. Pepys, MB, Hirschfield, GM. C-reactive protein: a critical update. JClin Invest 2003; 111(12): 1805-12.

13. Fröhlich M, Imhof A, Berg G, Hutchinson WL, Pepys MB, Boeing H, etal. Association between C reactive protein and features of the metabolic syndrome. Diabetes Care 2000; 23 (12): 1835-9.

14. Executive Summary of The Third Report of The National Cholesterol Education Program (NCEP) Expert Panel on Detection, Evaluation, And Treatment of High Blood Cholesterol In Adults (Adult Treatment Panel III). JAMA 2001; 285 (19): 2486-97.

15. Alberti, KG, Zimmet, P, Shaw, J. The metabolic syndrome - a new worldwide definition. Lancet 2005; 366 (9491): 1059-62.

16. Shishehbor, M.H.; Bhatt, D.L.; Topol, E.J. Using Creactive protein to assess cardiovascular disease risk. Cleve Clin. J. Med. 2003; 70 (7): 634-640.

17. Suzuki T, Voeks J, Zakai N.A,Jenny NS, Brown TM, Safford MM, et al. Metabolic syndrome, Creactive protein, and mortality in U.S. Blacks and Whites: The Reasons for Geographic and Racial Differences in Stroke (REGARDS) study. Diabetes Care. 2014;37(8): 2284-2290. doi: 10.2337/dc13-2059.

18. Sattar N, Gaw A, Scherbakova O,Ford I, O'Reilly DS, Haffner SM, etal. Metabolic syndrome with and without C-reactive protein as a predictor of coronary heart disease and diabetes in the West of Scotland Coronary Prevention Study.Circulation2003; 108(4): 414-19.

19. Rutter MK, Meigs JB, Sullivan LM, D'Agostino RB Sr, Wilson PW.C-reactive protein, the metabolic syndrome, and prediction of cardiovascular events in the Framingham Offspring Study. Circulation 2004; 110(4): 380-5.

20. Ramachandran A, Snehalatha C, SatyavaniK, Sivasankari S, Vijay V. Metabolic syndrome in urban Asian Indians adults: a population study using modified 
ATP III criteria. Diab Res Clin Pract2003; 60 (3): 199204.

21. The Seventh Report of the Joint National Committee on Prevention, Detection, Evaluation, and Treatment of High Blood Pressure: The JNC VII Report 2003; 289(19): 2560-71.

22. Gupta R, Deedwania PC, Gupta A, Rastogi S, Panwar RB, Kothari K. Prevalence of metabolic syndrome in an Indian urban population.Int $\mathrm{J}$ Cardiol 2004; 97(2): 257-61.

23. SudhaVidyasagar, UK Abdul Razak, CK Prashanth, D MuralidharVarma, KL Bairy. Highly sensitive Creactive protein in metabolic syndrome. JIACM 2013; 14 (3-4): 230-4.

24. Ridker PM, Buring JE, Cook NR, Rifai N. Creactive protein, the metabolic syndrome and risk of incident cardiovascular events: An 8 year follow-up of 14719 initially healthy American women. Circulation 2003;107(3):391-7.

25. Malik S, Wong ND, Franklin S, Pio J, Fairchild C, Chen R. Cardiovascular disease in U.S. patients with metabolic syndrome, diabetes and elevated c-reactive protein. Diabetes Care 2005;28(3):690-3.

26. Vikram NK, Misra A, Pandey RM, Dwivedi M, Luthra K, Dhingra V, et al. Association between subclinical inflammation and fasting insulin in urban young adult north Indian males. Indian J Med Res 2006;124(6):677-82.

27. Mukta N Chowta, Prabha M Adhikari, Rishav Sinha, Sahana D Acharya, HN Gopalakrishna, John T Ramapuram. Annals of Tropical Medicine and Public Health. 2012. 5(2). 98 - 102.
28. Pitsovas C, Panagiotakos DB, Tzima N, Lentzas Y, Chrysohoou C, Das UN, etal. Diet, exercise and CRP levels in people with abdominal obesity: the ATTICA epidemiological study. Angiology 2007; 58(2): 225- 33.

29. Miller WM, Memon I, Nori-Janosz KE et al. hsCRP in the morbidly obese: A predictor of conventional cardiovascular risk factors? Proceedings of 46th annual conference on cardiovascular disease epidemiology and prevention. Circulation2006; 113: E351.

30. Blake GJ, Rifai N, Buring JE, Ridker PM. Blood pressure, CRP and risk of future cardiovascular events. Circulation 2003; 108(24): 2993-9.

31. Picardi A, Valorani MG, Vespasiani Gentilucci, Manfrini S, Ciofini O, Cappa M, etal. Raised CRP levels in patients with recent onset type 1 diabetes. Diabetes Metab. Res Rev 2007; 23(3): 211-4.

32. Schillaci G, Pirro M. C-reactive protein in hypertension: clinical significance and predictive value. Nutr Metab Cardiovasc Dis 2006;16 (7): 500-8.

33. Doi Y, Kiyohara Y, Kubo M, Ninomiya T, Wakugawa Y, Yonemoto K, etal. Elevated Creactive protein is a predictor of the development of diabetes in a general Japanese population-The Hisayama Study. Diabetes Care 2005;28(10): 2497-500.

34. Steven M. Haffner SM. The metabolic syndrome: inflammation, diabetes mellitus, and cardiovascular disease. Am J Cardiol 2006; 97(Suppl): 3A-11A.

35. Grundy SM, Cleeman JI, Daniels SR, Donato KA, Eckel RH, Franklin BA, etal. Diagnosis and management of the metabolic syndrome: an American Heart Association /National Heart, Lung, and Blood Institute Scientific Statement. Circulation 2005; 112(17): 2735-52.

\section{How to cite this article?}

Ravi A, Thilak Babu, Shankar R. High Sensitive C-Reactive Protein as a Pro-inflammatory marker for the components of metabolic syndrome. Int J Med Res Rev 2016;4(6):889-895doi: 10.17511/ijmrr.2016.i06.05. 